\title{
Analysis and Reduction of Casting Defects in Handwheel through Numerical Simulation
}

\author{
R.Natarajan ${ }^{1}$, R.V.Krishnan ${ }^{2}$, S.Akash ${ }^{3}$, R.Harish kumar ${ }^{4}$ \\ rdh.prod@psgtech.ac.in, natarajan14121999@gmail.com,rvkrishnan786@gmail.com, \\ akashtqb06@gmail.com, \\ ${ }^{1-4}$ UG Students, Department of Production Engineering, PSG College of Technology, Coimbatore, \\ India, ${ }^{5}$ Assistant Professor, Department of Production Engineering, PSG College of Technology, \\ Coimbatore, India, ${ }^{6}$ Associate Professor, Department of Production Engineering, PSG College of \\ Technology, Coimbatore, India
}

\begin{abstract}
In today's competitive world foundry industries must be efficient to operate with minimum rejections and they should be able to manufacture casting components in a short lead time. Casting manufacturing is a process in which the molten material such as metal, plastics, etc is poured into the specifically designed hollow cavity of desired shape, called the mould and the material is allowed to solidify. The solidified part is called as a casting, which is broken out of the mold to complete the process. Still few foundries are working based on trial and error method to produce their casting. Most of the foundries focus very less on rejections, as they are always oriented towards production urgency; hence they ignore the rejections and salvage the castings. Defect free castings with minimum production cost have become the goal of the foundries. To produce castings with minimum rejections casting simulations software can play a major role. casting simulation aids in the visualization of phenomena like a solidification of casting and mold filling, and helps to identify the occurrence of related defects like shrinkage porosity, and can be also used for the optimizing the design parameters to achieve a high quality yield.
\end{abstract}

Keywords: Sand Casting, Casting Defect, Simulation, Optimization and Analysis.

\section{Introduction}

Metal casting being employed as the first step in the making most of the product. It is the commonly used method of manufacturing the desired shape of component. Sand casting is the mostly used casting process. In sand casting the pattern which is a replica of the end product is generated first, as like in any other casting methods, with the help of machining process. Then the sand mixture is prepared with different materials like silica sand, clay, olivine oil, moisture, lime etc. Sand mixture plays a major role in defining the quality of the sand casted products. Prepared sand mixture is rammed in the mould box with the pattern is placed inside the mold box. There are several types of pattern used like solid pattern, follow-board pattern, split pattern, loose piece pattern, gated pattern, sweep pattern, match-plate pattern cope and drag pattern, skeleton pattern etc., The molten metal is poured in the cavity made by the pattern inside the mold and wait until the metal solidifies. The product is obtained by breaking the mold after solidification is completed. Fettling operation is performed to clean and cut off the unwanted projections in the sand cast component. Sand casting also has its own limitation, 
which is specifically termed as casting defect. Sand casting has many types of casting defect and elimination of these defects is impossible due to the reason that it depends on many parameters of sand casting process. The only option is to minimize these casting defects as low as possible. Casting defects analysis, widely used for reducing the casting defects involves the process of analyzing the root cause for occurrence of defects in the rejection of casting. Its helps industries to take necessary steps to reduce the defects and to improve the casting yield. Various analysis techniques like cause-effect diagrams, design of experiments (DoE), casting simulation, if then rules (expert systems) and artificial neural networks (ANN) can be used for casting defects analysis. This work uses the numerical simulation technique, parameters of gating and riser for casting with multiple analysis characteristics in casting to analyze the effect of various gating system designs on cavity filling and casting quality using casting simulation software; satisfactory results were obtained with high yield.

In a leading foundry located in Coimbatore, Tamilnadu, hand wheel of 16 " diameter component which is sand casted, has been subjected to $14 \%$ of rejection due to casting defects such as air entrainment and shrinkage porosities. The main objective of this work is to analyze and eliminate the shrinkage porosity and the air entrainment defect in 16 " hand wheel by modifying the gating system and varying the process parameters using computer aided casting simulation software.

\section{Literature Review}

Atul A.Bhujugade et al [1] have presented on the casting defects minimization with the help of Casting Simulation Technique and performed casting defect analysis using Taguchi Method. The CAD model of the component (spider bearing) with high rejection percentage (12\%) was first created. Then the casting defects in the model were analyzed using the AutoCAST - X casting simulation software and checked for the occurrence of defects in the same part of the casting component. The simulation results showed shrinkage defect in the casting. The existing gating system was modified and a new gating system was designed using the theoretical formulae used for the gating and riser system design, direct chills were placed in the casting to achieve directional solidification. The new gating system with four cavities of mold with two separate in-gates to each casting, to increase the yield, +was modelled. The simulation results for the modified gating system were free of shrinkage defects. Then the process parameters of green sand casting that influences the shrinkage defect were identified, varied and response were recorded. The parameters considered are Moisture content, Sand particle size, Mold hardness and Pouring temperature. Using ANOVA and Minitab 16 software the optimal parameters producing castings with a very low rejection percentage were identified and the rejection percentage was reduced from $12 \%$ to $3.55 \%$.

Uday A.Dabade et al [2] used computer aided casting simulation software and (DoE) to analyse the casting defects. As the feeder was not feeding properly, the component Wheel hub was subjected to rejection due to shrinkage porosities. A new gating system was designed by modulus method and Caine's method of feeder design. The CAD model of the new gating system was modelled. Casting simulation and analysis is done with the existing and modified gating system model using Magmasoft software. A number of iterations for the gating system design of wheel hub were performed and the modified gating system with two feeders to feed four cavities mold with indirect chills in the core is found to be the optimal design. Then using $\mathrm{DoE}$, for the component turbocharger, various process parameters were varied and the optimal 
parameters were found using ANOVA. The rejection percentage for turbocharger was reduced from $10 \%$ to $3.59 \%$.

Avinash Jurian et al [3] have presented on the casting defect analysis in Foundry and their remedial measures with Industrial Case studies. The data was analyzed using Ishikawa Cause and Effect diagram. The major casting defects were studied along with their causes and their remedial measures were provided in this journal. The paper was referred for remedial measures of various casting defects and they were adopted in our project for reducing the rejection percentage of the component which we have chosen.

Harshil Bhatt et al [4] have presented on the elimination of shrinkage defect by modifying the feeding system design. The casing of gear box was subjected to high rejection percentage due to shrinkage, cold shut, crack and mismatch defects. The locations and dimensions of riser were altered to eliminate the defects and the response was noted. From the results the optimum location and dimensions of riser were obtained after performing a number of iterations by altering the parameters of riser.

Bhupendra J.Chudasama et al [5] have presented on the solidification analysis and optimization using ProCAST. The paper presents on the effect of riser and runner height on shrinkage porosity percentage. The bearing housing is simulated a number of times by varying the runner and riser height. The optimal runner and riser height were decided based on the simulation results, on the reduction in the shrinkage porosity percentage.

Sheikh A.K et al [6] did a comparative study on simulation software for modelling metal casting processes. The methodology, solution methods, defects predictions and material database of various casting software were discussed in the paper. The advantages of one software over the other were presented in the paper. From the paper, ProCAST software is found to be more realistic and accurate in defects prediction and it also provides the possibility of adding any casting alloy properties to the database.

\section{Methodology}

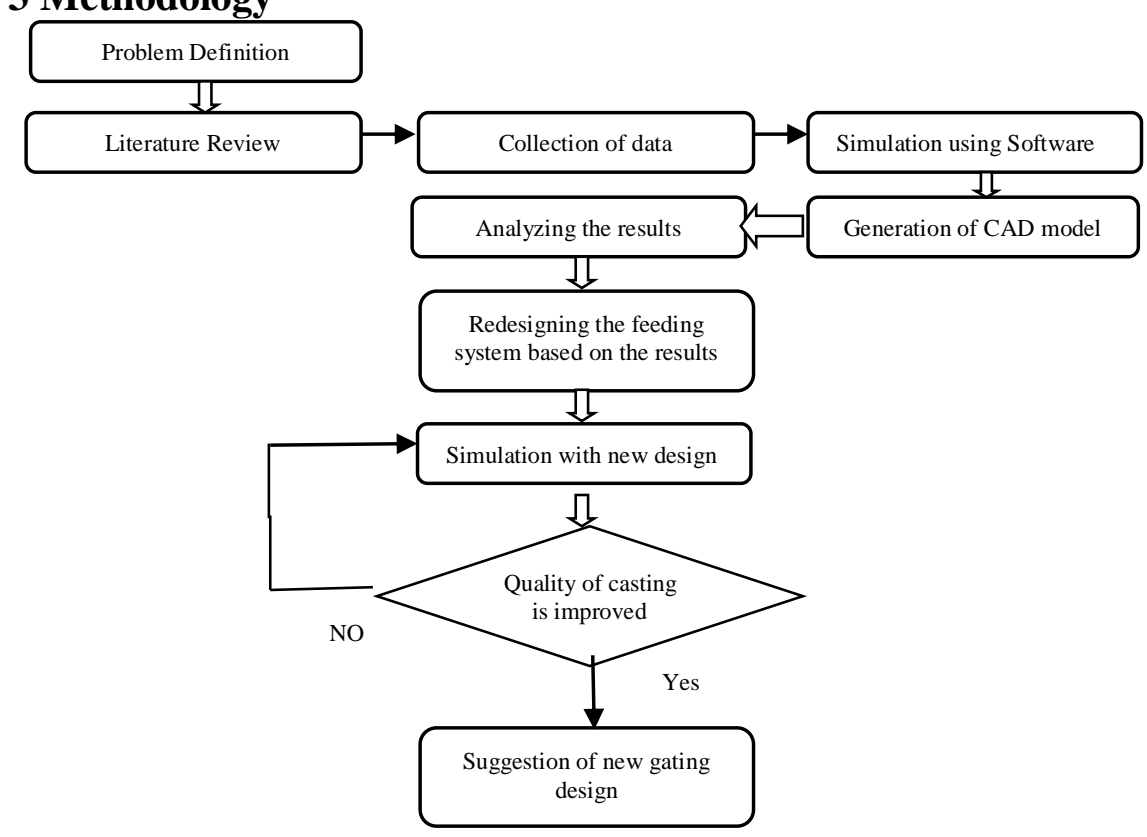


Fig. 1 Methodology

A component (hand wheel of 16") which has a higher rate of rejection due to voids and blow holes in the foundry division is chosen for study. Observations of various parameters involved during casting process are noted down. 3D CAD model for the component along with runner, riser, sprue, ingate is created using PTC creo parametric 6.0.2.0 with the help of the dimensions noted. Separate CAD models are created for component and mold box and fed as input in IGES format to casting simulation software, which is used for performing the casting simulations. Analysis was performed with the created model using simulation software by giving collected parameters as input. Formation of Defects were observed during the simulation, root cause of such defects were studied and various parameters like pouring temperature, riser size, riser locations and vent holes locations were adjusted until the defects were minimized in simulation.

\section{Simulation Software}

Simulation software used to analyse the flow of molten metal in the mold and the heat dissipation. Industries use the software to design mold size, gating system, vent holes location and riser dimensions etc., and predict the quality of cast products. During the simulation Porosity in the component is easily visualised and its helps in understanding thermal microstructure and porosity calculations including inoculation. Simulation software uses microstructure solver to compute the density variations on the casting component. Simulations can be performed for changes in many variables to suit the exact condition of the casting environment.

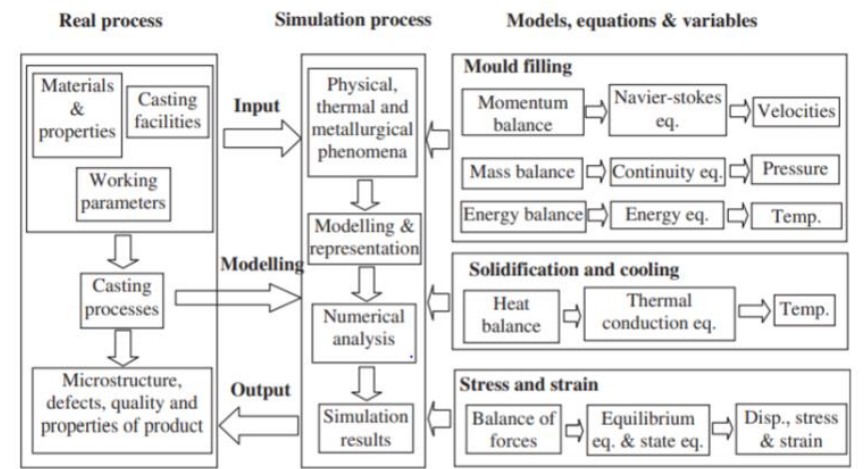

Fig.2 Relationship between process, modelling, simulation and output variable

Finite Element Method is used by the software to discretize the complete domain of the problem into small pieces, termed as elements. A structured mesh for filling and solidification simulations is provided by simulation software. Mesh generator can perform surface mesh and Boolean operation on casting component. Casting software performs various numerical calculations with the generated mesh block to provide us with the reliable simulation. It is the currently the reliable software to simulate all types of casting processes, predict all the major casting defects and has a wide variety of material database. Softwares are designed to be user friendly hence most casting industries prefer using the same. Software can be used for casting optimization which in turn can provide the process condition and/or casing design automatically to manufacture component with desired quality and optimal manufacturing conditions. It can perform design optimization which can suggest best design for riser location 
and dimensions, Chill locations, Ingate positions and Runner dimensions. Using the software optimal values for the major process variables like pouring temp, pouring rate which can be used to prevent wrapping or reduce the porosity formation and other defects in the casting.

\section{Information About Casting Part}

Existing parameters used are listed in Table.1.

Table.1 Existing Casting conditions

\begin{tabular}{|c|c|}
\hline Parameters & Values \\
\hline Mold box size & $640 \times 480 \times 160 \mathrm{~mm}$ \\
\hline Melting temp & $1435^{\circ} \mathrm{C}$ \\
\hline Pouring temp & $1397^{\circ} \mathrm{C}$ \\
\hline Molding sand & Green sand \\
\hline Pouring time & $6-7$ secs \\
\hline Pouring weight & $10 \mathrm{~kg}$ \\
\hline Gross weight & $7.8 \mathrm{~kg}$ \\
\hline Net weight & $5.9 \mathrm{~kg}$ \\
\hline Casting yield & $75 \%$ \\
\hline
\end{tabular}

Green sand composition used for molding is Silica sand : $1.6 \mathrm{~g} / \mathrm{cm}^{3}$, New sand : $40 \mathrm{~kg}$, Return sand : $1100 \mathrm{~kg}$, Coal dust : $3.5 \mathrm{~kg}$, Bentonite powder : $10 \mathrm{~kg}$. Properties of the molding sand are Moisture content : 3 - 3.6\%, Compactability : 38 - 48\%, Green compression strength : 18 - 24psi, Permeability number : 120 - 220, Loss of ignition : $4-5.5 \%$, Loss of volatile : 2 $3.5 \%$, Total clay percentage : 10 - 14\%, Active clay : 7 - 10\%, Dead clay : 3 - 5\%, AFS number : $40-70$. Rejection percentage of the component: $14 \%$ (due to blow holes and voids).

\section{Analysis And Identification Of Defects In Existing Gating System}

Based on the collected data in the existing design, it was found that the component was fed with a top gating system. The metal enters the mold cavity directly from the riser and therefore yield obtained is higher. The turbulence is high in the top gating system and the air aspiration is also high. The gating ratio of the existing gating system is 2:1 i.e pressurized gating system is used for casting the component. As per the drawing of component with the existing gating system, the CAD model is created using Creo parametric 6.0 and is saved in IGES format.

Once the CAD model of the component is created, mold box of required size $(640 \times 480 \times 320 \mathrm{~mm})$ was modelled over the component using Creo parametric 6.0 which is also saved in IGES format. The CAD model of the component and mold box is given as input to the casting simulation software, for simulation analysis of the casting defects in the component with the existing parameters and gating design used in foundry is performed. 


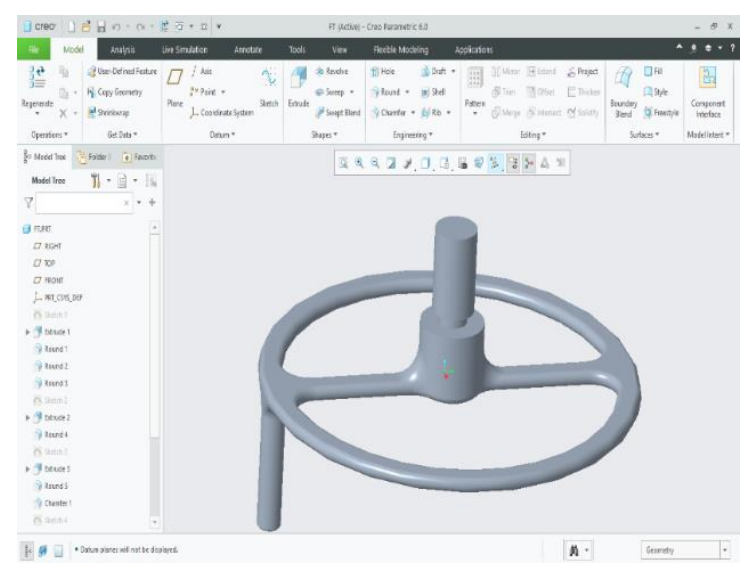

Fig.3 CAD model of component along with existing gating system

The CAD model of existing component is simulated using software. Existing process parameters were given as inputs to the software. The parameters include Melting temperature of $1435^{\circ} \mathrm{C}$, Pouring temperature of $1397^{\circ} \mathrm{C}$, Molding sand: Green sand, Pouring time: 6-7 seconds and other parameters used in foundry. Then the simulation was run and it predicted the voids formation. It can be observed from the simulation data that the voids are formed because of the turbulence, air aspiration resulting from existing gating system. In the shown simulation figure (Fig.4), the region in red shows the high air entrainment area in the component. This simulation result is similar to the actual site inspection results of the components which are being casted. Based on the simulation result we can understand that the air entrainment defect is due to the improper gating design and due to the lack of vent holes for the gases from the molten metal to escape through the mold cavity.

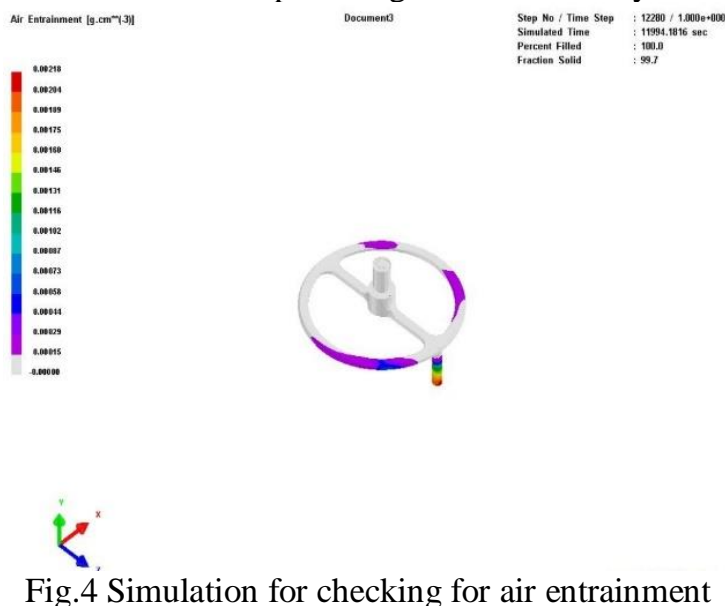

\section{Results And Discussions}

Based on the results from the simulation, few trials were performed by varying the process parameters and the gating design, to find the optimum parameter values for casting 
and concluded that the following parameters yield better results compared to the casting design. The parameters varied are Pouring Temperature: $1350^{\circ} \mathrm{C}$, Riser Height: $95 \mathrm{~mm}$, Riser location: Above the area of air entrainment, Vent hole location : Near the sprue.

The pouring temperature was reduced to avoid the high emission of gases resulting in the air entrainment in casting. The sprue height was modified as per the Caine's method and Modulus method to compensate for the shrinkage porosities in the casting. The riser location was shifted so that the metal first fills the region of high entrainment and avoids the air bubble formation in the casting. The vent holes are provided for the exhaust of gases to avoid the air bubble formation in the casting. The simulation results for various parameters were analyzed and the optimal parameters for eliminating the defects were identified. To eliminate the void and air entrainment defect in the hand wheel, the existing gating system was modified by placing the sprue in a new location, above the cylindrical extrusion of the component and a vent hole was placed $100 \mathrm{~mm}$ away from the sprue.

Based on the analysis and simulation study, optimum parameters were identified and the CAD model was generated. The CAD model was saved in iges format and imported to the simulation software platform for analysis and verification. Simulation is now performed for the modified gate design and for the new parameters. Then a model of the component with a modified gating system and a relocated vent hole was simulated and the results obtained were free from voids and air entrainment defects.

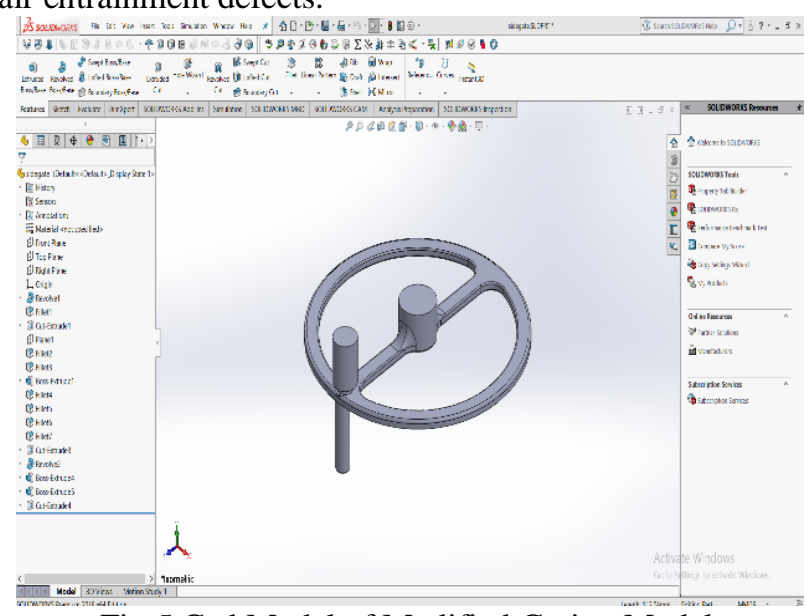

Fig.5 Cad Model of Modified Gating Model

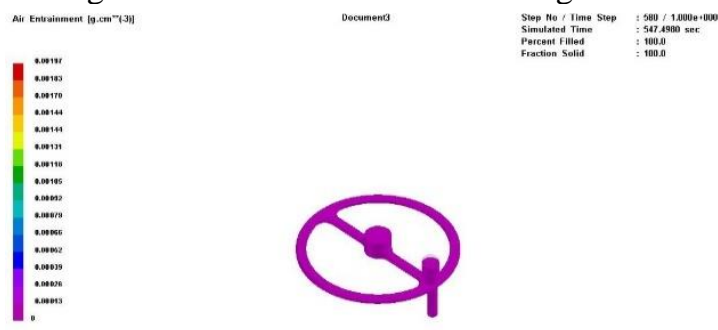

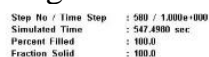

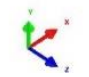

Fig.6 Cast simulation for air entrainment in new model 
One can see from the simulated result that the vent hole provided helps in escape of gases from the molten metal poured into the cavity. As the sprue location is shifted, the molten metal first enters the region where the air entrainment defect occurred in the component's existing gating design. So the metals first fill the cylindrical extruded region and thus the air bubbles formation in the casting is avoided.

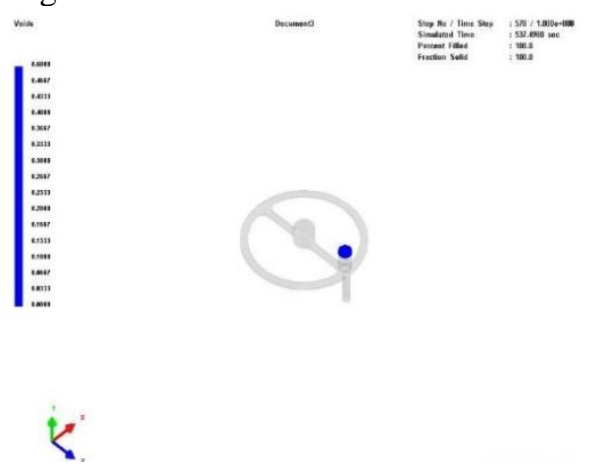

Fig.7 Cast simulation for voids in new model

Figure7 shows that voids previously located in the casting have been completely eliminated and component produced using the new gating design have no voids. Simulation software used for the design of method of casting offers several advantages such as; the time consumed to perform casting defect analysis is very much reduced as compared to the conventional method of design. And the cost involved in the conventional trial and error method was eliminated with the usage of software. It helps the users to visualize the phenomenon of mold filling thus making it easy for the user to understand the process. Simulation can be used to identify the hotspots, where there is a high chance for the occurrence of defects. The results obtained using casting defects analysis offers the advantage of improved yield, reduced rejection of cast components and high cost reduction that was earlier spent on conventional trial and error method. The lead time to manufacture the component has also been drastically reduced due to the usage of simulation software.

\section{Conclusion}

Casting simulation can minimize the wastage of resources required for trial production. In addition, the optimization of quality and yield implies higher value addition and lower production cost, improving the margins. The 16" Hand wheel component was found to be defect free when simulated using simulation software, after modifying the gating system and placing a vent hole near the sprue, thus the defects were eliminated and the rejection percentage of the component will be reduced by adopting the modified feeding design in the system. The time required by the followed method is very less as compared to the conventional method. Visualization of metal flow inside the mold helps for the easy to understanding and to determine the cause of defect.

\section{References}

[1] Atul A.Bhujugade, Vijay B.Sabnis, "Minimization of Casting Defects Using Casting Simulation Technique and Casting Defect Analysis Using Design of Experiment" International Journal for Research in Applied Science \& Engineering Volume 3, Issue 6, June 2015. 
[2] Uday A.Dabade, Rahul C.Bhedasgaonkar, "Casting Defect Analysis using Design of Experiments (DoE) and Computer Aided Casting Simulation Technique" Procedia CIRP 7, 2013, PP 616 - 621.

[3] Harshil Bhatt, Rakesh Barot, Kamlesh Bhatt, Hardik Beravala, Jay Shah, "Design Optimization of Feeding System and Solidification Simulation for Cast Iron" Procedia Technology CIRP 14, 2014, PP 357-364.

[4] Avinash Juriani, "Casting Defect Analysis in Foundry and Their Remedial Measures with Industrial Case studies" IOSR Journal of Mechanical and Civil Engineering Volume 12, Issue 6, December 2015,PP 43-54.

[5] Khan, Sheikh A.K, "A Comparative Study of Simulation Software for Modelling Metal Casting Processes" IJSIMM 2018, PP 197-209.

[6] Bhupendra J.Chudasama, "Solidification Analysis and Optimization Using ProCAST" International Journal of Research in Modern Engineering and Engineering Technology Volume 1, Issue 4, May 2013. 